\title{
COOPERACION INTERNACIONAL AL PROCESO EN JUZGADOS SONORENSES
}

\author{
(Breve estudio sobre la colaboración del Supremo Tribunal de Justicia en \\ diligenciamiento y desahogo de pruebas procedentes del extranjero: 2017)
}

Eusebio Francisco Flores Barraza*
Yesenia Gastelum Ortega*

Sumario: I. Introducción. II. Desarrollo. III. Conclusiones.

\section{Resumen.}

La cooperación procesal internacional que deriva de los exhortos y cartas rogatorias recibidas del exterior llegan a nuestros tribunales para ser diligenciadas conforme a los tratados y convenciones de los que México es parte y derivado del trafico jurídico internacional. Después de una búsqueda minuciosa (en un periodo de 3 años), en los tribunales del Estado de Sonora, con información complementaria, observamos una serie de indicadores que nos arroja determinados indicadores que descubrimos y que detallamos en este modesto ensayo elaborado desde nuestra academia de derecho internacional.

Palabras claves: Exhorto, Derecho Procesal y Tratados Internacionales

\section{Abstract.}

The international procedural cooperation that derives from the letters and rogatory letters received from abroad come to our courts to be processed according to the treaties and conventions of which Mexico is a party and derived from international legal traffic. After a thorough search (in a period of 3 years), in the courts of the State of Sonora, with complementary information, we observe a series of indicators that show us important results discovered and that we detail in this modest essay, elaborated from our academy of international right.

Keywords: Request, rogatory letters, Procedural Law, International Treaties

\footnotetext{
* Docente-Investigador de TC del Departamento de Derecho de la Universidad de Sonora, DCS, URC, Doctor en Derecho por la Universidad de La Habana, Cuba, doctoreusebioippson@live.com.mx "Docente-Investigador de TC de la Universidad de Sonora, Doctora por el Centro de Estudios Superiores en Ciencias Jurídicas y Criminológicas Unidad de Enlace Sonora.
} 


\section{Résumé.}

La Coopération International de procédure que vient des cartes rogatoires et mandants reçues du l'extérieur arrivent à notres tribunaux pour être des procédures judiciaires en respetant des traités et conventions que Mexique fait partie dérivé du trafic juridique international Après d'une recherche minutieuse ( en periode de trois ans ), les tribunaux de l'État du Sonora, avec des renseignements complaimentaires, nous notons une série des indicareurs que nous donne des impotantes résultats rencontrés et que nous peufinons dans cette travail, réalisé depuis notre académie de Droit International

Mots clés: mandants, Droit Procédural et Traités Internationaux

\section{"las palabras de la ley deben pesarse como diamantes"}

J. Bentham.

\section{Introducción.}

En el marco de la cooperación procesal internacional seguimos --aceitando las ruedas de la carreta con arena-, es bien conocido por el gremio litigante falta de conocimiento y apreciación del derecho procesal internacional. Cuando observamos un tratado o acuerdo internacional emanado de la Organización de Estados Americanos $^{1}$ o de la Conferencia de la Haya sobre Derecho Internacional Privado ${ }^{2}$, cuyos tratados de cada uno de estos organismos rectores son poco conocidos o a veces ignorados por los operadores jurídicos en nuestro medio. El presente trabajo constituye un breve ensayo de seguimiento y calificación de los juzgados estatales del Poder Judicial de nuestro Estado, afín de darle continuidad, conocimiento y divulgación a los tratados mas útiles en el desempeño correcto de la cooperación procesal en el plano internacional.

Creemos que una de las labores del docente investigador es vincular la academia con el organismo operador de la norma, no se debe de perder esa esencia afín de caminar juntos para la divulgación correcta de nuestro derecho.

\footnotetext{
${ }^{1}$ http://www.oas.org/es/sla/ddi/tratados_acuerdos.asp

${ }^{2}$ https://www.hcch.net/es/states/hcch-members/details1/?sid=54
} 
Ningún jurista puede sentirse orgulloso, si solo sabe su derecho, porque no lo compara y lo complementa con otro. Ese otro es el derecho positivo convencional que entra y regula nuestro derecho local de la misma manera que el suyo propio.

Es factible que nadie quiera salir de su zona de confort para explorar derecho internacional, creyendo errónanemanete que ya sabe todo. No hay nada mas equivocado que esto último, vamos arriesgándonos a conocer los acuerdos firmados y ratificados por México y porque no, los que están en vías de consolidación, finalmente serán norma y derecho positivo en su momento oportuno.

En la realización del presente trabajo intervienen e involucra a muchos actores, pero los yerros son de marca y acentuación personal.

\section{Cooperación Procesal Internacional}

En el Derecho internacional Privado "están las reglas destinadas a regular la vida de las personas y familias a nivel internacional y también...las transacciones comerciales internacionales que son el motor del sistema capitalista actual" ${ }^{3}$

Derivado de lo anterior y en una búsqueda, no fácil de información de todos los exhortos o cartas rogatorias ${ }^{4}$ recibidas del extranjero únicamente y/o diligenciadas por los tribunales civiles y mercantiles durante el período de 2014 a 2016, expedientes que "transitan" en los juzgados del Estado de Sonora; encontramos que en tres años a la fecha se ha mantenido una colaboración notable en función de cooperación procesal internacional.

Ante lo cual desarrollamos el presente ensayo, con la información que se nos proporciona que consideramos valiosa para la academia y el foro sonorense I.

La -competencia delegada- ${ }^{5}$ tema generalmente complejo en nuestra disciplina jurídica, recae en el juez sonorense para facilitar y cooperar con otra instancia judicial

\footnotetext{
${ }^{3}$ Pereznieto Castro, Leonel; Estado, Sociedad y Derecho, ED. LIMUSA,; “ interdisciplinariedad del Derecho Internacional", pág. 310, Ed. 2016

${ }^{4}$ Eduardo Juan Couture Etcheverry ( citado por Silva Silva), "afirma que la palabra exhorto es una voz culta, derivada del verbo exhortar, compuesto de hortar- ari, estimular animar", de su obra vocabulario jurídico, J.A. Silva Silva, pág. 485, Derecho Internacional sobre el Proceso; Ed. Porrúa, México, año:2014

5 “... la competencia indirecta el órgano posee la capacidad para cooperar a un proceso extranjero o ejecutar una resolución extranjera (cooperar ejecutando el acto solicitado en el exhorto).
} 
en el extranjero. A través de un exhorto o carta rogatoria, recibida en el tribunal sonorense se finca automáticamente la competencia internacional indirecta, por lo que el tribunal del estado receptor, en este caso el sonorense actuará de manera inmediata, mandando diligenciar con providencia y esmero necesario el legajo correspondiente.

Sin embargo el tema no es tan sencillo, dado que el tribunal receptor no tiene datos confiables a la mano, por un supuesto "temor" a que se amparen las personas involucradas en las notificación o requerimiento de otra índole; esta situación complica la búsqueda minuciosa de los legajos 0 expediente con las correspondientes actuaciones originales. Lo más lamentable para nuestras autoridades judiciales es que si cooperamos con el trámite del tratado involucrado, pero no queda asentado fielmente datos precisos y sobre todo copia fiel de las actuaciones, son muy escasos los datos duros que pudieren abonar al respecto. No obstante la academia por nuestro conducto ha estado tratado de convencerlos que dejen mayor prueba de las actuaciones y no solo un breve anotación en libros que francamente no dicen mucho al respecto.

\section{Desarrollo}

De la información recaba a la solicitud de la academia ${ }^{6}$ de conformidad con los artículos $6^{\circ}$ de la Constitución Política de los Estados Unidos Mexicanos; artículos 22 fracción II, 124, 129 y demás relativos aplicables de la Ley de Trasparencia y Acceso a la información Pública del Estado de Sonora, y en el acuerdo que emitió la Unidad de Trasparencia, quedó asentado la solicitud de información de todos los exhortos o cartas rogatorias recibida del extranjero únicamente y/o diligenciadas por los Tribunales civiles y mercantiles ${ }^{7}$ durante el periodo de 2014 a 2016.

\footnotetext{
....Tómese nota que al que se le atribuye la competencia indirecta tiene una doble tarea. Por un lado, revisar que posee la competencia para poder cooperar o ejecutar y, por el otro, que ese ejecutor (de manera indirecta), revisa o comprueba si el que conoció o resolvió poseía competencia en la esfera internacional." Supra ob.cit.pag. 184-185

${ }^{6}$ Registrada con folios 011070216 y 01161916 , según oficio No. UE.- 544/16, Hermosillo, Sonora a 29 de septiembre del 2016.

${ }^{7}$ El eximio profesor y amigo; Silva Silva, menciona:"El hecho es que en la zona fronteriza mexicana (objeto de mi atención)los exhortos fronterizos (ejecutados por los jueces) asumen la materia familiar como parte de la materia civil expresada en la Convención. De la laboral no tengo antecedentes. Hasta ahora nadie ha dicho nada que
} 


\section{En atención a esta información ${ }^{8}$, observamos lo siguiente:}

A. Con respecto a la procedencia de los exhortos o cartas rogatorias procedentes del extranjero, anotamos:

9 expedientes provenientes de: Arizona, USA

4 expedientes recibidos de California, USA

1 expediente de Pensilvania, USA

1 expediente de Texas, USA

1 expediente de Washington, USA

1 expediente de Suiza, UE

1 expediente de Alemania, UE

B. 19 casos comprendidos en un período de 3 años.

C. En cuanto a la materia involucrada en la cooperación. Todos los casos que observamos son de naturaleza Civil.

D. Igualmente del total de casos, el 99\% fueron diligenciados.

E. Prácticamente la mayoría de nuestra colaboración procesal es con el estado de Arizona, USA.

contradiga esta admisión, ni judicial ni doctrinariamente. Soy de la opinión de que los tribunales del trabajo también pueden participar de los beneficios de esta Convención, y en algún otro lugar así lo he dicho”, pág. 233 de su artículo de revista electrónica: EXHORTO FRONTERIZO. ALGUNAS EXPERIENCIAS EN LA ZONA FRONTERIZA CIUDAD JUÁREZ-EL PASO:REVISTA REDALYC

${ }^{8}$ Agradecemos las atenciones del Lic. Carlos Duarte Rodríguez, por su valiosa colaboración en la información recabada para la realización de este modesto ensayo jurídico. 


\section{ZONA ${ }^{9}$ INVOLUCRADA EN EL TRAFICO JURIDICO INTERNACIONAL:}

\section{ESTADOS}

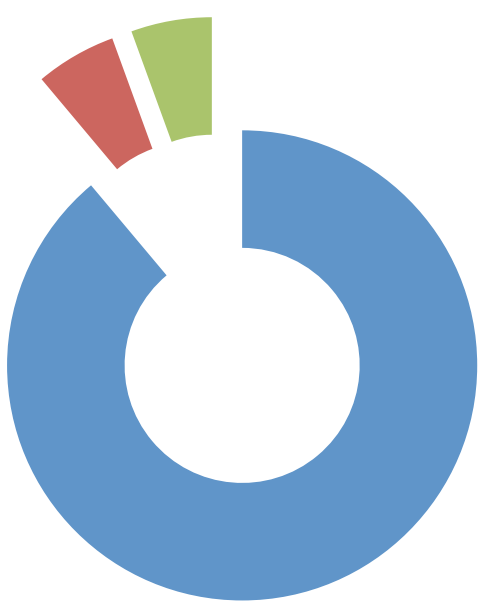

- I.USA

2.SUIZA

3.ALEMANIA

Observaciones. De los $19^{10}$ casos involucrados en materia de cooperación procesal internacional a través de exhortos o cartas rogatorias el $89 \%$ provienen de USA, el resto: $12 \%$ de la UE.

\section{CIUDAD/ESTADO}
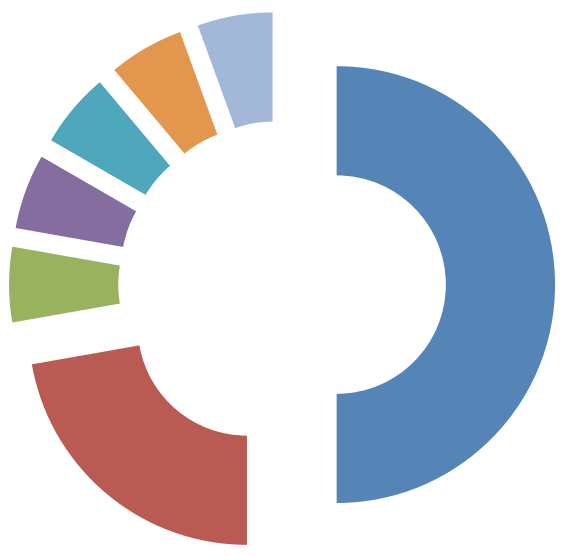

$$
\begin{aligned}
& \text { A.ARIZON,USA } \\
& \text { B.CALIFORNIA,USA } \\
& \text { C.TEXAS,USA } \\
& \text { D.PENSILVANIA,USA } \\
& \text { E.WASHINGTON,USA } \\
& \text { F.SUIZA } \\
& \text { G.ALEMANIA }
\end{aligned}
$$

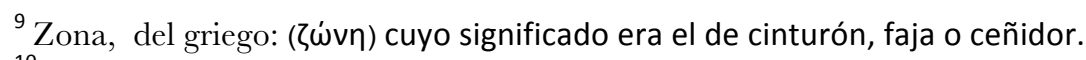

${ }^{10} \mathrm{El}$ profesor y amigo Silva J.A., menciona "En su parte central, el informe anota lo siguiente: "se atendieron 781 exhortos, abrieron 233 cuadernillos de ejecución de ejecutorias de amparo, ocho cartas rogatorias, cuatro excitativas de justicia, tres restitución de menores y se atendieron a más de 267 personas para su orientación". Respecto de una investigación similar con exhortos fronterizos Cd. Juárez - el Paso Texas, USA; Chihuahua, s/e, enero de 2014.pag.220, opus citae; http://www.redalyc.org/articulo.oa?id=42747919007 
Observaciones. El $50 \%$ de los casos relativos a la cooperación por la vía en estudio, provienen del estado de Arizona, USA. Razón de más para abundar en la importancia judicial con este estado fronterizo.

\section{Conclusiones}

- Por lo que respecta a la información que se nos proporcionó, por parte de la Unidad de Enlace, no se distingue la diferencia entre exhorto o carta rogatoria procedente del extranjero.

- No hay en nuestros tribunales del estado un seguimiento puntual, y asentado por escrito, que evidencie la colaboración de nuestros tribunales con el resto del mundo. Pareciere ser no quisiéramos que se enteraran de este trascendental mecanismo de colaboración que coloca y posiciona a nuestro estado de Sonora en el trafico jurídico internacional.

- Observamos un escenario incipiente de 19 casos de cooperación en un periodo de 3 años.

- Es evidente que la cooperación procesal internacional, que sostienen nuestros juzgados en el Estado de Sonora fundamentalmente son en materia Civil, con los Estados Unidos, particularmente con el estado de Arizona, US.

Incipientemente, aparece una colaboración con solo dos países de la Unión Europea: Suiza y Alemania.

- No aparece en el rubro de estudio, ningún caso de colaboración en materia Mercantil o Comercial, por lo que por increíble que parezca suponemos (sin llegar a afirmar) que esto se está llevando a cabo por conducto de la figura del common law, denominado "commissioners" o comisionados que de manera extrajudicial brindan en fase de pre trial, un servicio excepcional al proceso norteamericano

- Quedan algunas respuestas pendientes en la labor de auscultación de los expedientes sonorenses, en materia de colaboración, que sin lugar a dudas tenderemos que esperar un tiempo prudente e insistir para encontrar dichas respuestas pertinentes que pueda iluminar el final del túnel que representa la cooperación procesal internacional, con el resto de los tribunales de otros países. 
- Este breve ensayo quedara inacabado, hasta seguir insistiendo en el trámite correspondiente al Derecho Procesal Internacional, que nuestros tribunales del Estado de Sonora pudieren brindar; el foro sonorense deberá seguir intentándolo, vale la pena saber... que sí se trabaja y no se simula.

\section{Bibliografía}

Pereznieto Castro Leonel; Derecho Internacional Privado, Parte Especial, ED. Oxford University Press, Edición 2012, México. DF.

Pereznieto Castro, Leonel; Estado, Sociedad y Derecho

Silva Silva, Jorge Alberto; Derecho Internacional sobre el Proceso; ED. Porrúa Edición 2011, México, DF.

Silva Silva Jorge Alberto; Artículo de Revista Electrónica parte del acervo de la Biblioteca Jurídica Virtual del Instituto de Investigaciones Jurídicas de la UNAM:

Exhorto Fronterizo. Algunas experiencias en la zona fronteriza Ciudad Juárez MX.- El Paso, TX, 2016

\section{Legislación}

Constitución Política de los Estados Unidos mexicanos

Colegio de Profesores de Derecho Procesal de la Facultad de Derecho de la UNAM; Diccionario de Derecho Procesal

Azar Elías, Edgar; Frases y Expresiones Latinas; ED. Porrúa, Ed. 2003, México D.F. Ley General de Transparencia y Acceso a la Información Pública del Estado de Sonora 2016

http://www.oas.org/es/sla/ddi/tratados_acuerdos.asp

https://www.hcch.net/es/states/hcch-members/details1/?sid=54 